\author{
Roman Szkup \\ Uniwersytet Łódzki \\ Katedra Geografii Miast i Turyzmu \\ 90-142 Łódż, ul. Kopcińskiego 31 \\ tel. 048426354566 \\ rasz@geo.uni.lodz.pl
}

\title{
ORGANIZACJA PRZESTRZENI WYPOCZYNKU INDYWIDUALNEGO W STREFIE PODMIEJSKIEJ EODZI
}

\section{WSTEP}

Wzrastające zapotrzebowanie na wypoczynek prowadzi do stopniowego opanowywania bardzo różnorodnych geograficznie obszarów przez szeroko rozumiane zjawiska turystyczne. W efekcie także i przestrzeń podmiejska każdego wielkiego miasta staje się powszechnie wykorzystywana do celów turystyczno-wypoczynkowych. W przestrzeni podmiejskiej realizowane są bardzo różne formy wypoczynku - w strefie podmiejskiej Lodzi dominuje wypoczynek letniskowy i weekendowy organizowany indywidualnie (MATCZAK 1987, SZKUP 2003).

Podmiejską przestrzeń turystyczno-wypoczynkową najprecyzyjniej opisują tereny trwale zajmowane pod wypoczynek, czyli kolonizowane turystycznie. Przyjęcie takiego założenia prowadzi do utożsamienia procesu kształtowania się podmiejskiej przestrzeni turystyczno-wypoczynkowej $\mathrm{z}$ ksztaltowaniem się przestrzeni kolonizacji turystycznej danego obszaru (SzKuP 2003). Zgodnie Z definicja przestrzeni kolonizacji turystycznej LISZEWSKIEGO (1995), „dominującym przejawem działalności turystycznej czlowieka (w przestrzeni kolonizacji turystycznej) jest trwałe zajmowanie i zagospodarowanie turystyczne nowych ziem zmieniające ich pierwotne użytkowanie; wiąże się to ściśle $\mathrm{z}$ powstawaniem domów wczasowych, hoteli, pensjonatów, ośrodków wypoczynkowych, kolonijnych itp. oraz drugich domów i działek letniskowych".

\section{THE ORGANIZATION OF INDIVIDUAL RECREATION SPACE IN THE RURAL-URBAN FRINGE ZONE OF ŁÓDŹ}

\section{INTRODUCTION}

The growing demand for recreation leads to very different geographical areas being gradually subordinated to a wide variety of tourism phenomena. The ruralurban fringe zone of every large city is popularly used for tourism and recreation purposes. In urban fringe space a great variety of recreational forms occur and in the urban fringe zone of Łódz it is individually organized summer and weekend recreation that dominates (MATCZAK 1987, SZKUP 2003).

Urban fringe tourism, and its recreational space, is best described as an area permanently occupied for recreation, i.e. touristically colonized. If we assume this, the process of creating an urban fringe tourism space is the same as the creation of a tourist colonization space in a given area (SzKUP 2003). According to LISZEWSKI's (1995) definition of tourism colonization space, 'the dominating manifestation of human tourist activity is the permanent acquisition and exploitation of new land for tourism involving a change in its original use; it is connected specifically with the building of new holiday centres, hotels, pensions etc., as well as second houses and summer gardens...'. 
Wyniki badań podmiejskiej przestrzeni wypoczynkowej prowadzone przez wielu badaczy, w tym w ośrodku łódzkim - m.in. przez MATCZAKA (1981, 1982, 1984, 1985, 1986, 1987, 1995), WILUSIA, (1997), WOJCIECHOWSKA (1998), WŁODARCZYKA $(1995,1998)$ oraz SzKUPA $(2003)$ - pozwolity temu ostatniemu w pracy Ksztaltowanie się podmiejskiej przestrzeni wypoczynkowej. Przykład zachodniego sektora strefy podmiejskiej Lodzi (2003) dowodzić, że podmiejską przestrzeń kolonizacji turystycznej (czy, synonimowo - wypoczynkowej lub turystyczno-wypoczynkowej) tworzą dwie podprzestrzenie (przestrzenie), odmienne z punktu widzenia przejawów przestrzennego zagospodarowania oraz zachowań turystycznych zbiorowości ludzkich je tworzących: podmiotów prawnych (instytucji) i podmiotów fizycznych (obywateli):

- przestrzeń wypoczynku zbiorowego - definiowana jako podprzestrzeń kolonizacji turystycznej przez LISZEWSKIEGO (1995) - kreowana przez podmioty prawne $\mathrm{w}$ formie obiektów stałych bazy noclegowej wypoczynku zbiorowego;

- przestrzeń wypoczynku indywidualnego - definiowana jako podprzestrzeń kolonizacji turystycznej przez LISZEWSKIEGO (1995) - kreowana przez podmioty (osoby) fizyczne w formie obiektów indywidualnego wypoczynku letniskowego (działek letniskowych i drugich domów).

$\mathrm{Z}$ prac prowadzonych przez wcześniej wymienianych autorów jednoznacznie wynika, że w strefie podmiejskiej Łodzi w procesie kolonizacji turystycznej przestrzeń wypoczynku zbiorowego odgrywa zdecydowanie mniejszą rolę. O obliczu wypoczynkowym strefy podmiejskiej Łodzi decyduje de facto przestrzeń wypoczynku indywidualnego. SzKUP (2003), podsumowując szczególowe badania nad kolonizacją turystyczną w zachodniej części (sektorze) strefy podmiejskiej Łodzi, stwierdza: „To właśnie rozwój obiektów wypoczynku indywidualnego (działek letniskowych) doprowadził do wykształcenia się specyficznego obrazu przestrzeni wypoczynkowej sektora - dysproporcje pomiędzy skalą ilościową oraz przestrzennym rozmieszczeniem form turystycznego osadnictwa indywidualnego i osadnictwa wypoczynku zbiorowego są tak ogromne, iż nie ma podstaw wątpić, że to wlaśnie rozwój obiektów wypoczynku indywidualnego (dzialek letniskowych) jest czynnikiem decydującym o obrazie przestrzeni wypoczynkowej tej części strefy podmiejskiej Łodzi."

Proces kształtowania się przestrzeni wypoczynku indywidualnego w strefie podmiejskiej Łodzi powoduje daleko idące przekształcenia w jednostkach
Research into urban fringe recreational space by MATCZAK (1981, 1982 , 1984, 1985, 1986, 1987, 1995), WILUŚ (1997), WoJcIEchowsKA (1998), WŁoDARCZYK $(1995,1998)$ and SZKUP (2003), among others from the Łódź centre, allowed the last-named to claim that urban fringe tourism colonization space is composed of two subspaces differing as regards infrastructure and the tourist behaviour of both institutions and individual citizens (in: Kształtowanie sie podmiejskiej przestrzeni wypoczynkowej. Przyktad zachodniego sektora strefy podmiejskiej Łodzi, 2003):

1) Collective recreation space, defined as a tourism colonization subspace by LISZEWSKI (1995), created by institutions in the form of accommodation facilities for the purposes of collective recreation;

2) Individual recreation space, defined as a tourism colonization subspace by LISZEWSKI (1995), created by individuals in the form of summer gardens and second houses.

The results obtained by the authors listed above clearly show that collective recreation space plays a considerably less important role than individual recreation space in the process of tourism colonization in the urban fringe zone of Łódź. In concluding a detailed study of tourism colonization in the western sector of the urban fringe zone of Łódź, SzKuP (2003) states: 'It was the development of individual recreation facilities (summer gardens) that led to the creation of a specific recreational space in the sector; the differences between the number and spatial distribution of individual tourism settlement forms and collective recreation settlement forms are so immense that the development of individual recreation facilities (summer gardens) determines the recreational space in this part of Lódź urban fringe zone.'

The creation of individual recreation space in the Łódż rural-urban fringe has caused far-reaching transformations in the settlements in this zone. Analysing tourism settlement in the Warta Valley, WILUS (1997) states that the process of 
osadniczych tę strefę tworzących. WILUŚ (1997), analizując osadnictwo turystyczne w dolinie Warty, stwierdza, że „proces kolonizacji turystycznej (...) powoduje szereg zmian w układach przestrzennych wielu miejscowości (...), dotyczą one przede wszystkim budowy morfologicznej i fizjonomii jednostek osadniczych." Zdaniem wielu badaczy zmiany układów przestrzennych miejscowości pod wplywem zjawisk szeroko powiązanych $\mathrm{z}$ turystyką uważane są za wskaźnik identyfikacji osiedli pelniących funkcję turystyczną i wypoczynkową (MATCZAK, 1984, DZIEGIEĆ 1988, 1989, WILUŚ 1997, STACHOWSKI, 1992, SzKUP 2003). Przekształcenia jednostek osadniczych pod wplywem rozprzestrzeniania się obiektów wypoczynku indywidualnego, czyli działek letniskowych, nie są jednorodne - $w$ różnorodny sposób i w różnej skali przekształceniom podlegają bowiem zarówno siedliska, jak i wiejskie rozłogi.

\section{KRYTERIA TYPOLOGII}

Różnorodność oraz skala zjawiska rozprzestrzeniania się działek letniskowych skłonily autora niniejszej pracy do podjęcia próby poszukiwania podobieństw w organizacji przestrzeni wypoczynku indywidualnego w jednostkach osadniczych strefy podmiejskiej Łodzi. Pierwszą próbę tworzenia typologii fizjonomiczno-morfologicznej jednostek osadniczych w strefie podmiejskiej Łodzi podją WILUŚ (1997), analizując osadnictwo turystyczne w dolinie Warty. Autor niniejszego opracowania, zainspirowany wspomnianą typologia, przedstawił W cytowanej wcześniej pracy (SzKUP 2003) własną typologię, którą nazwał „typologią przestrzeni wypoczynku indywidualnego w zachodnim sektorze strefy podmiejskiej Łodzi." Podstawą do stworzenia tej typologii stały się badania własne autora prowadzone w latach 1995-1998 w 260 obrębach geodezyjnych na 7525 działkach letniskowych, zlokalizowanych w zachodnim sektorze strefy podmiejskiej Łodzi. Po opublikowaniu wymienionej typologii podjęto próbę jej „weryfikacji” podobnymi badaniami przeprowadzonymi $\mathrm{w}$ polożonym w południowo-zachodniej części strefy podmiejskiej Łodzi powiecie łaskim. Wspomniane badania autor przeprowadził w latach 2004-2005 wspólnie z T. Dronką i w ich efekcie dokonal identyfikacji przestrzeni wypoczynku indywidualnego na 2820 działkach letniskowych położnych w 134 sołectwach powiatu. Jako kryteria wydzielenia określonych typów organizacji przestrzeni wypoczynku indywidualnego przyjęto: tourism colonization (...) has caused numbers of changes in the space of many destinations (...); they mainly concern the morphological composition and physiognomy of settlements.' According to many researchers, housing estates which perform tourism and recreational functions are an identifying indicator of the transformations caused by tourismrelated phenomena (MATCZAK 1984, DZIEGIEĆ 1988, 1989, WILUŚ 1988, STACHOWSKI 1992, SzKuP 2003). The transformations of settlements caused by the spreading of individual recreation facilities are not homogenous; settlements and open countryside are transformed in differing ways and to a different extent.

\section{TYPOLOGY CRITERIA}

The diversity and scale of the summer garden phenomenon encouraged the author to attempt to find similarities in the organization of individual recreation space in the settlements of the ruralurban fringe zone of Łódz. The first attempt to create a physiognomic and morphological typology was made by WILUŚ (1997) in analysing tourist settlements in the Warta Valley. Inspired by this typology, the author presented (SzkuP 2003) his own typology in his work quoted above. He called it 'a typology of individual recreation space in the western sector of the Łódż rural-urban fringe zone'. It was based on research conducted in 1995-1998 in 260 grid squares and 7525 summer gardens in this western sector. After the typology had been published there were attempts to verify it through similar studies in Łask powiat in the south-western part of the urban fringe zone. The author did the research in 2004-2005, in cooperation with Dronka, and as a result identified individual recreation space in 2820 summer gardens in 134 sotectwos of the powiat. The criteria for identifying the types of organization of individual recreation space were the following: 
1) zwartość i/lub rozproszenie układów działek letniskowych w obrębach geodezyjnych lub solectwach; na podstawie tego kryterium wydzielono:

- obręby lub sołectwa, w których zdecydowanie dominują dzialki koncentrujące się $\mathrm{w}$ zwartych kompleksach (44 obręby zachodniego sektora i 42 solectwa powiatu laskiego),

- obręby lub solectwa, w których działki występują zarówno w postaci rozproszonej, jak i w kompleksach (39 obrębów zachodniego sektora i 21 sołectw powiatu łaskiego),

- obręby lub sołectwa, w których działki występują wyłącznie w postaci rozproszonej (33 obręby zachodniego sektora i 41 solectw powiatu laskiego);

2) położenie działek letniskowych w stosunku do głównego siedliska (siedlisk) obrębu lub sołectwa; opierając się na tym kryterium wydzielono:

- obręby lub solectwa, w których dzialki są wyłącznie na rozłogach wiejskich (70 obrębów i 71 solectw),

- obręby lub sołectwa, w których działki położone są na rozlogach wiejskich i w siedlisku (siedem obrębów zachodniego sektora i trzy solectwa powiatu laskiego),

- obręby lub sołectwa, w których działki położone sq̨ wyłącznie w siedlisku (sześć obrębów zachodniego sektora i 10 sołectw powiatu łaskiego);

3) rozplanowanie dzialek w obrębach i solectwach (wg MATCZAKA 1984); na podstawie tego kryterium wydzielono:

- obręby lub sołectwa, w których dominują układy przestrzenne działek regularne, zwarte, o typie parkowym (jeden obręb zachodniego sektora - Siedlątków),

- obręby lub sołectwa, w których dominują układy przestrzenne działek regularne, zwarte, jednolub wieloosiowe (17 obrębów zachodniego sektora i 17 sołectw powiatu laskiego),

- obręby lub sołectwa, w których dominują układy przestrzenne dzialek nieregularne, zwarte, wieloosiowe (14 obrębów zachodniego sektora i 10 solectw powiatu łaskiego),

- obręby lub sołectwa, w których dominują układy przestrzenne działek nieregularne, rozproszone, mozaikowe (42 obręby zachodniego sektora i 43 solectwa powiatu laskiego),

- obręby lub solectwa, w których dominują układy przestrzenne działek nieregularne, rozproszone, występujące incydentalnie - pojedyncze działki (40 obrębów zachodniego sektora i 13 solectw powiatu łaskiego);

4) stopień przekształcenia obrębu lub sołectwa przez osadnictwo turystyczne; operając się na tym kryterium wydzielono:
1) concentration and/or dispersion of summer gardens in grid squares or sołectwos:

- strongly dominated by compact garden complexes (44 squares, 42 solectwos),

- where gardens are both dispersed and in complexes (39 squares, 21 sotec- $^{-}$ twos),

- where there are only dispersed summer gardens (33 squares, 41 sotectwos);

2) location of summer gardens in relation to the main settlements in the grid square or sołectwo. Summer gardens occur:

- exclusively on open countryside $(70$ squares, 71 sotectwos),

- on open countryside and in a settlement ( 7 squares, 3 sotectwos)

- exclusively in a settlement (6 squares, 10 sotectwos);

3) distribution of summer gardens within grid squares and solectwos (according to MATCZAK, 1984) dominated by summer garden systems which were:

- regular, compact, park-type (one square - Siedlatków),

- regular, compact, one- or multi-axis

(17 squares, 17 sotectwos),

- irregular, compact, multi-axis (14 squares, 10 sotectwos),

- irregular, dispersed, mosaic (42 squares, 43 sotectwos),

- irregular, dispersed, incidental single gardens (40 squares, 13 sołectwos),

4) the extent to which a grid square or sotectwo has been changed by tourist settlement, where both settlements and the majority of the open countryside have been changed:

- completely by complexes of summer gardens (4 squares, 8 sotectwos),

- considerably (20 squares, 24 sołectwos),

- slightly (92 squares, 51 sołectwos);

5) the proportion of grid squares or sotectwos occupied by forms of individual tourist settlement where:

- the overall area of the gardens exceeds the area of the settlement and the gardens cover over $10 \%$ of the area (7 squares, 6 sołectwos), 
- obręby lub solectwa, w których jednostki osadnicze (siedliska) oraz większość rozłogów zostały przez kompleksy działek przekształcone całkowicie (cztery obręby zachodniego sektora i osiem solectw powiatu laskiego),

- obręby lub sołectwa, w których jednostki osadnicze (siedliska) oraz większość rozłogów zostały przez kompleksy działek przekształcone znacząco (20 obrębów zachodniego sektora i 24 sołectw powiatu łaskiego),

- obręby lub solectwa, w których jednostki osadnicze (siedliska) oraz większość rozlogów zostały przez kompleksy działek przekształcone nieznacznie (92 obręby zachodniego sektora i 51 solectw powiatu łaskiego);

5) wielkość zajmowanej przestrzeni obrębu lub solectwa przez formy indywidualnego osadnictwa turystycznego; na podstawie tego kryterium wydzielono:

- obręby lub solectwa, w których łączna powierzchnia działek przewyższa powierzchnię siedliska, a same dzialki zajmuja pond $10 \%$ powierzchni obrębu (siedem obrębów zachodniego sektora i sześć solectw powiatu laskiego),

- obręby lub sołectwa, w których łączna powierzchnia działek nie przewyższa powierzchni siedliska, a same działki zajmują od 3 do $10 \%$ powierzchni obrębu (13 obrębów zachodniego sektora i siedem sołectw powiatu łaskiego),

- obręby lub solectwa, w których niewielkie kompleksy działek zajmują małą część obrębu 0,5-3\% calkowitej powierzchni (49 obrębów zachodniego sektora i 27 solectw powiatu laskiego),

- obręby lub sołectwa, w których działki letniskowe zajmują marginalną część obrębów - mniej niż $0,5 \%$ powierzchni calkowitej obrębu (45 obrębów zach. sektora i 41 solectw powiatu laskiego);

6) dominująca wielkość powierzchni dzialek letniskowych w obrębie lub solectwie (KOWALCZYK 1994 - zmodyfikowane); opiejąc się na wymienionym kryterium wydzielono:

- obręby lub solectwa, w których dominuja działki duże, o powierzchni większej od $2000 \mathrm{~m}^{2}$ (21 obrębów zachodniego sektora i osiem solectw powiatu łaskiego),

- obręby lub solectwa, w których dominuja działki średnie, o powierzchni 1001-2000 $\mathrm{m}^{2}$ (71 obrębów zachodniego sektora i 45 solectw powiatu laskiego),

- obręby lub sołectwa, w których dominują działki małe, o powierzchni $800-1000 \mathrm{~m}^{2}$ (21 obrębów zachodniego sektora i 28 sołectw powiatu laskiego),
- the overall area of the gardens does not exceed the area of the settlement and the gardens cover $3-10 \%$ (13 squares, 7 sotectwos),

- small complexes of gardens cover 0.5-3\% (49 squares, 27 sołectwos),

- summer gardens cover less than $0.5 \%$ (45 squares, 41 sołectwos);

6) the dominant size of gardens in a grid square or sołectwo (KowALCZYK 1994 - modified);

- large - more than $2000 \mathrm{~m}^{2}$ (21 squares, 8 sotectwos),

- medium - 1001-2000 m² (71 squares, 45 solectwos),

- small - 800-1000 m² (21 squares, 28 sołectwos),

- very small - less than $800 \mathrm{~m}^{2}$ (3 squares, 2 sotectwos).

Based on the specifications and analysis of the criteria mentioned above, seven types of individual recreation space organization have been identified in the grid squares and sotectwos of the Łódź urban fringe zone (table I). The criterion applied to put the types in an order was the level of concentration of summer gardens in the grid square. Therefore, the determinant of the first four types of grid square (types I, II, III and IV) was domination by compact summer garden complexes; and that of the last three (types V, VI and VII) - the domination of dispersed gardens. Due to the considerable differences in garden sizes within the squares in types I, III and IV, sub-types have been identified as well (Ia, Ib, IIIa, IIIb, IVa and IVb).

The final stage of the organization of individual recreation spaces within grid squares, was their allocation to individual types and the preparation of cartograms presenting the spatial distribution of the identified types (figs 1 \& 2). 
T a b e I a I. Charakterystyka typów organizacji przestrzeni wypoczynku indywidualnego obrębów geodezyjnych i sołectw na wybranych obszarach strefy podmiejskiej Łodzi

\begin{tabular}{|c|c|c|c|c|c|c|c|c|c|c|}
\hline \multirow{2}{*}{$\begin{array}{c}\text { Kryterium } \\
\text { oceny }\end{array}$} & \multicolumn{10}{|c|}{ Typy organizacji przestrzeni } \\
\hline & la & $\mathrm{Ib}$ & $\|$ & Illa & Illb & IVa & $\mathrm{IVb}$ & V & VI & VII \\
\hline $\begin{array}{l}1 . \\
\text { Położenie } \\
\text { działek ze } \\
\text { względu } \\
\text { na ich } \\
\text { zwartość }\end{array}$ & $\begin{array}{l}\text { w zwartych } \\
\text { komplek- } \\
\text { sach lub } \\
\text { dominacja } \\
\text { zwartych } \\
\text { komplek- } \\
\text { sów }\end{array}$ & $\begin{array}{l}\text { W zwartych } \\
\text { komplek- } \\
\text { sach lub } \\
\text { dominacja } \\
\text { zwartych } \\
\text { komplek- } \\
\text { sów } \\
\end{array}$ & $\begin{array}{l}\text { w zwartych } \\
\text { komplek- } \\
\text { sach lub } \\
\text { dominacja } \\
\text { zwartych } \\
\text { komplek- } \\
\text { sów }\end{array}$ & $\begin{array}{l}\text { w zwartych } \\
\text { komplek- } \\
\text { sach lub } \\
\text { dominacja } \\
\text { zwartych } \\
\text { komplek- } \\
\text { sów }\end{array}$ & $\begin{array}{l}\text { w zwartych } \\
\text { komplek- } \\
\text { sach lub } \\
\text { dominacja } \\
\text { zwartych } \\
\text { komplek- } \\
\text { sów }\end{array}$ & $\begin{array}{l}\text { w zwartych } \\
\text { komplek- } \\
\text { sach lub } \\
\text { dominacja } \\
\text { zwartych } \\
\text { komplek- } \\
\text { sów }\end{array}$ & $\begin{array}{l}\text { W zwartych } \\
\text { komplek- } \\
\text { sach lub } \\
\text { dominacja } \\
\text { zwartych } \\
\text { komplek- } \\
\text { sów }\end{array}$ & $\begin{array}{l}\text { rozproszo- } \\
\text { ne lub do- } \\
\text { minacja } \\
\text { działek roz- } \\
\text { proszonych }\end{array}$ & $\begin{array}{l}\text { rozproszo- } \\
\text { ne lub do- } \\
\text { minacja } \\
\text { działek roz- } \\
\text { proszonych }\end{array}$ & $\begin{array}{l}\text { rozpro- } \\
\text { szone lub } \\
\text { dominacja } \\
\text { działek roz- } \\
\text { proszonych }\end{array}$ \\
\hline $\begin{array}{l}2 . \\
\text { Położenie } \\
\text { działek } \\
\text { w stosun- } \\
\text { ku do } \\
\text { siedliska } \\
\end{array}$ & $\begin{array}{l}\text { na rozło- } \\
\text { gach lub } \\
\text { większośśc } \\
\text { na rożo- } \\
\text { gach }\end{array}$ & $\begin{array}{l}\text { na rozło- } \\
\text { gach lub } \\
\text { większość } \\
\text { na rozło- } \\
\text { gach }\end{array}$ & $\begin{array}{l}\text { na rozło- } \\
\text { gach lub } \\
\text { większość } \\
\text { na rozło- } \\
\text { gach }\end{array}$ & $\begin{array}{l}\text { na rozło- } \\
\text { gach lub } \\
\text { większość } \\
\text { na rozło- } \\
\text { gach }\end{array}$ & $\begin{array}{l}\text { na rozło- } \\
\text { gach lub } \\
\text { większość } \\
\text { na rozło- } \\
\text { gach }\end{array}$ & $\begin{array}{l}\text { na rozło- } \\
\text { gach lub } \\
\text { większość } \\
\text { na rozło- } \\
\text { gach }\end{array}$ & $\begin{array}{l}\text { na rozło- } \\
\text { gach lub } \\
\text { większość } \\
\text { na rozło- } \\
\text { gach }\end{array}$ & $\begin{array}{l}\text { na rozło- } \\
\text { gach lub } \\
\text { większośc } \\
\text { na rozło- } \\
\text { gach }\end{array}$ & $\begin{array}{l}\text { na rozło- } \\
\text { gach lub } \\
\text { większośc } \\
\text { na rozło- } \\
\text { gach }\end{array}$ & $\begin{array}{l}\text { w siedlisku } \\
\text { lub domina- } \\
\text { cja poło- } \\
\text { żonych } \\
\text { w siedlisku }\end{array}$ \\
\hline $\begin{array}{l}3 . \\
\text { Rozplano- } \\
\text { wanie } \\
\text { działek }\end{array}$ & $\begin{array}{l}\text { układy } \\
\text { regularne, } \\
\text { zwarte, } \\
\text { jedno- lub } \\
\text { wielo- } \\
\text { osiowe }\end{array}$ & $\begin{array}{l}\text { układy } \\
\text { regularne, } \\
\text { zwarte, } \\
\text { jedno lub } \\
\text { wielo- } \\
\text { osiowe }\end{array}$ & $\begin{array}{l}\text { układy } \\
\text { nieregular- } \\
\text { ne, rozpro- } \\
\text { szone, } \\
\text { mozaikowe }\end{array}$ & $\begin{array}{l}\text { układy } \\
\text { regularne, } \\
\text { zwarte, jed- } \\
\text { no- lub } \\
\text { wielo- } \\
\text { osiowe }\end{array}$ & $\begin{array}{l}\text { układy } \\
\text { regularne, } \\
\text { zwarte, jed- } \\
\text { no- lub } \\
\text { wielo- } \\
\text { osiowe }\end{array}$ & $\begin{array}{l}\text { uklady } \\
\text { nieregular- } \\
\text { ne, rozpro- } \\
\text { szone, } \\
\text { mozaikowe }\end{array}$ & $\begin{array}{l}\text { układy } \\
\text { nieregular- } \\
\text { ne, rozpro- } \\
\text { szone, } \\
\text { mozaikowe }\end{array}$ & $\begin{array}{l}\text { uklady } \\
\text { nieregular- } \\
\text { ne, rozpro- } \\
\text { szone, two- } \\
\text { rzace nie- } \\
\text { wielkie } \\
\text { kompleksy }\end{array}$ & $\begin{array}{l}\text { uklady } \\
\text { nieregular- } \\
\text { ne, rozpro- } \\
\text { szone, } \\
\text { występuja- } \\
\text { ce incyden- } \\
\text { talnie } \\
\end{array}$ & $\begin{array}{l}\text { układy } \\
\text { nieregular- } \\
\text { ne, rozpro- } \\
\text { szone, } \\
\text { występuja- } \\
\text { ce incyden- } \\
\text { talnie } \\
\end{array}$ \\
\hline $\begin{array}{l}4 . \\
\text { Stopień } \\
\text { przekształ } \\
\text {-cenia } \\
\text { obrebu } \\
\end{array}$ & duży & duży & duży & maty & mały & mały & mały & $\begin{array}{l}\text { bardzo } \\
\text { mały }\end{array}$ & minimalny & minimalny \\
\hline \begin{tabular}{|l}
5. \\
Wielkość \\
zajmowa- \\
nej prze- \\
strzeni \\
obrębu \\
\end{tabular} & $\begin{array}{l}\text { duża i bar- } \\
\text { dzo duża } \\
>3-30 \%\end{array}$ & $\begin{array}{l}\text { duża i bar- } \\
\text { dzo duża } \\
>3-30 \%\end{array}$ & $\begin{array}{l}\text { duża } \\
3-10 \%\end{array}$ & $\begin{array}{l}\text { niewielka } \\
0,5-3 \%\end{array}$ & $\begin{array}{l}\text { niewielka } \\
0,5-3 \%\end{array}$ & $\begin{array}{l}\text { niewielka } \\
0,5-3 \%\end{array}$ & $\begin{array}{l}\text { niewielka } \\
0,5-3 \%\end{array}$ & $\begin{array}{l}\text { minimalna } \\
<0,5 \%\end{array}$ & $\begin{array}{l}\text { minimalna } \\
<0,5 \%\end{array}$ & $\begin{array}{l}\text { minimalna } \\
<0,5 \%\end{array}$ \\
\hline $\begin{array}{l}6 . \\
\text { Dominuja- } \\
\text { ca wiel- } \\
\text { kośc } \\
\text { działek }\end{array}$ & $\begin{array}{l}\text { Średnie } \\
\text { i duże } \\
>1000 \mathrm{~m}^{2}\end{array}$ & $\begin{array}{l}\text { małe } \\
\mathrm{i} \text { bardzo } \\
\text { małe - do } \\
1000 \mathrm{~m}^{2} \\
\end{array}$ & $\begin{array}{l}\text { Średnie } \\
\text { i duże } \\
>1000 \mathrm{~m}^{2}\end{array}$ & $\begin{array}{l}\text { Srednie } \\
\text { iduże } \\
>1000 \mathrm{~m}^{2}\end{array}$ & $\begin{array}{l}\text { małe } \\
\text { ibardzo } \\
\text { małe - do } \\
1000 \mathrm{~m}^{2} \\
\end{array}$ & $\begin{array}{l}\text { Średnie } \\
\text { i duże } \\
>1000 \mathrm{~m}^{2}\end{array}$ & $\begin{array}{l}\text { małe } \\
\text { i bardzo } \\
\text { małe - do } \\
1000 \mathrm{~m}^{2} \\
\end{array}$ & $\begin{array}{l}\text { średnie } \\
\text { i duże } \\
>1000 \mathrm{~m}^{2}\end{array}$ & $\begin{array}{l}\text { średnie } \\
\text { i duże } \\
>1000 \mathrm{~m}^{2}\end{array}$ & $\begin{array}{l}\text { średnie } \\
\text { i duże } \\
>1000 \mathrm{~m}^{2}\end{array}$ \\
\hline
\end{tabular}

Żródło: Opracowanie własne.

- obręby lub solectwa, w których dominują działki bardzo małe, o powierzchni mniejszej niż $800 \mathrm{~m}^{2}$ (trzy obręby zachodniego sektora i dwa sołectwa powiatu łaskiego).

$\mathrm{Na}$ podstawie sumarycznych zestawień oraz analizy wymienionych kryteriów wydzielono siedem typów organizacji przestrzeni wypoczynku indywidualnego $\mathrm{w}$ analizowanych obrębach geodezyjnych i solectwach strefy podmiejskiej Łodzi (tab. I). Za kryterium porządkujące wydzielone typy przyjęto zwartość działek w obrębach $-\mathrm{z}$ tego też względu wyznacznikiem pierwszych czterech typów obrębów (typy: I, II, III i IV) stała się dominacja na obszarze obrębów zwartych kompleksów działek letniskowych, trzech ostatnich (typy: V, VI i VII) - dominacja działek rozproszonych.

\section{DESCRIPTION OF INDIVIDUAL TYPES}

Type I - The type of grid square or solectwo where individual recreation settlements (summer gardens) have developed the most. It is dominated by compact complexes of summer gardens situated mainly on open countryside and organized in regular, one- or two-axis compact spatial systems. The extent to which the original grid square space has been transformed by summer settlement is large or very large, and the area occupied by summer houses is 3\%-30\% (the 
T a b I e I. Types of individual recreation space organization within grid squares and sołectwos in selected parts of the Łódź rural-urban zone

\begin{tabular}{|c|c|c|c|c|c|c|c|c|c|c|}
\hline \multirow{2}{*}{ Criterion } & \multicolumn{10}{|c|}{ Types of spatial organization } \\
\hline & la & $\mathrm{lb}$ & II & IIla & Illb & $\mathrm{IVa}$ & $\mathrm{IVb}$ & V & $\mathrm{VI}$ & VII \\
\hline $\begin{array}{l}1, \\
\text { Gardens } \\
\text { according } \\
\text { to spatial } \\
\text { form }\end{array}$ & $\begin{array}{l}\text { In compact } \\
\text { complexes } \\
\text { or } \\
\text { dominantly } \\
\text { so }\end{array}$ & $\begin{array}{l}\text { In compact } \\
\text { complexes } \\
\text { or } \\
\text { dominantly } \\
\text { so }\end{array}$ & $\begin{array}{l}\text { In compact } \\
\text { complexes } \\
\text { or } \\
\text { dominantly } \\
\text { so }\end{array}$ & $\begin{array}{l}\text { In compact } \\
\text { complexes } \\
\text { or } \\
\text { dominantly } \\
\text { so }\end{array}$ & $\begin{array}{l}\text { In compact } \\
\text { complexes } \\
\text { or } \\
\text { dominantly } \\
\text { so }\end{array}$ & $\begin{array}{l}\text { In compact } \\
\text { complexes } \\
\text { or } \\
\text { dominantly } \\
\text { so }\end{array}$ & $\begin{array}{l}\text { In compact } \\
\text { complexes } \\
\text { or } \\
\text { dominantly } \\
\text { so }\end{array}$ & $\begin{array}{l}\text { Dispersed } \\
\text { gardens } \\
\text { or } \\
\text { dominantly } \\
\text { so }\end{array}$ & $\begin{array}{l}\text { Dispersed } \\
\text { gardens } \\
\text { or } \\
\text { dominantly } \\
\text { so }\end{array}$ & $\begin{array}{l}\text { Dispersed } \\
\text { gardens } \\
\text { or } \\
\text { dominantly } \\
\text { so }\end{array}$ \\
\hline $\begin{array}{l}2 . \\
\text { Location of } \\
\text { gardens in } \\
\text { relation to } \\
\text { settlement }\end{array}$ & $\begin{array}{l}\text { On open } \\
\text { countryside } \\
\text { or mostly so }\end{array}$ & $\begin{array}{l}\text { On open } \\
\text { countryside } \\
\text { or mostly so }\end{array}$ & $\begin{array}{l}\text { On open } \\
\text { countryside } \\
\text { or mostly so }\end{array}$ & $\begin{array}{l}\text { On open } \\
\text { countryside } \\
\text { or mostly so }\end{array}$ & $\begin{array}{l}\text { On open } \\
\text { countryside } \\
\text { or mostly so }\end{array}$ & $\begin{array}{l}\text { On open } \\
\text { countryside } \\
\text { or mostly so }\end{array}$ & $\begin{array}{l}\text { On open } \\
\text { countryside } \\
\text { or mostly so }\end{array}$ & $\begin{array}{l}\text { On open } \\
\text { countryside } \\
\text { or mostly so }\end{array}$ & $\begin{array}{l}\text { On open } \\
\text { countryside } \\
\text { or mostly so }\end{array}$ & $\begin{array}{l}\text { Gardens } \\
\text { in the } \\
\text { settlement } \\
\text { or mostly so }\end{array}$ \\
\hline $\begin{array}{l}\text { Distribu- } \\
\text { tion of } \\
\text { gardens }\end{array}$ & $\begin{array}{l}\text { Regular } \\
\text { compact } \\
\text { systems, } \\
\text { one- or } \\
\text { multiaxis } \\
\text { systems }\end{array}$ & $\begin{array}{l}\text { Regular } \\
\text { compact } \\
\text { systems, } \\
\text { one- or } \\
\text { multiaxis } \\
\text { systems }\end{array}$ & $\begin{array}{l}\text { Irregular, } \\
\text { dispersed, } \\
\text { mosaic } \\
\text { systems }\end{array}$ & $\begin{array}{l}\text { Regular } \\
\text { compact } \\
\text { systems, } \\
\text { one- or } \\
\text { multiaxis } \\
\text { systems }\end{array}$ & $\begin{array}{l}\text { Regular } \\
\text { compact } \\
\text { systems, } \\
\text { one- or } \\
\text { multiaxis } \\
\text { systems }\end{array}$ & $\begin{array}{l}\text { Irregular, } \\
\text { dispersed, } \\
\text { mosaic } \\
\text { systems }\end{array}$ & $\begin{array}{l}\text { Irregular, } \\
\text { dispersed, } \\
\text { mosaic } \\
\text { systems }\end{array}$ & $\begin{array}{l}\text { Irregular, } \\
\text { dispersed } \\
\text { systems, } \\
\text { small } \\
\text { complexes }\end{array}$ & $\begin{array}{l}\text { Irregular, } \\
\text { dispersed, } \\
\text { incidental } \\
\text { systems }\end{array}$ & $\begin{array}{l}\text { Irregular, } \\
\text { dispersed, } \\
\text { incidental } \\
\text { systems }\end{array}$ \\
\hline $\begin{array}{l}4 . \\
\text { Grid } \\
\text { square } \\
\text { trans- } \\
\text { formation }\end{array}$ & $\begin{array}{l}\text { Consider- } \\
\text { able }\end{array}$ & $\begin{array}{l}\text { Consider- } \\
\text { able }\end{array}$ & $\begin{array}{l}\text { Consider- } \\
\text { able }\end{array}$ & Small & Small & Small & Small & Very small & Minimal & Minimal \\
\hline $\begin{array}{l}5 . \\
\text { Area of } \\
\text { grid } \\
\text { square } \\
\text { occupied }\end{array}$ & $\begin{array}{l}\text { Large } \\
\text { or very } \\
\text { large } \\
>3-30 \%\end{array}$ & $\begin{array}{c}\text { Large } \\
\text { or very } \\
\text { large } \\
>3-30 \%\end{array}$ & $\begin{array}{l}\text { Large } \\
3-10 \%\end{array}$ & $\begin{array}{c}\text { Small } \\
0.5-3 \%\end{array}$ & $\begin{array}{c}\text { Small } \\
0.5-3 \%\end{array}$ & $\begin{array}{c}\text { Small } \\
0.5-3 \%\end{array}$ & $\begin{array}{c}\text { Small } \\
0.5-3 \%\end{array}$ & $\begin{array}{l}\text { Minimal } \\
<0.5 \%\end{array}$ & $\begin{array}{l}\text { Minimal } \\
<0.5 \%\end{array}$ & $\begin{array}{l}\text { Minimal } \\
<0.5 \%\end{array}$ \\
\hline $\begin{array}{l}6 . \\
\text { Dominant } \\
\text { garden } \\
\text { size }\end{array}$ & $\begin{array}{c}\text { Medium } \\
\text { or large } \\
>1000 \mathrm{~m}^{2}\end{array}$ & $\begin{array}{c}\text { Small } \\
\text { or very } \\
\text { small } \\
<1000 \mathrm{~m}^{2}\end{array}$ & $\begin{array}{l}\text { Medium } \\
\text { or large } \\
>1000 \mathrm{~m}^{2}\end{array}$ & $\begin{array}{c}\text { Medium } \\
\text { or large } \\
>1000 \mathrm{~m}^{2}\end{array}$ & $\begin{array}{c}\text { Small } \\
\text { or very } \\
\text { small } \\
<1000 \mathrm{~m}^{2}\end{array}$ & $\begin{array}{l}\text { Medium and } \\
\quad \text { large } \\
>1000 \mathrm{~m}^{2}\end{array}$ & $\begin{array}{c}\text { Small } \\
\text { and very } \\
\text { small } \\
<1000 \mathrm{~m}^{2}\end{array}$ & $\begin{array}{c}\text { Medium and } \\
\quad \text { large } \\
>1000 \mathrm{~m}^{2}\end{array}$ & $\begin{array}{l}\text { Medium } \\
\text { or large } \\
>1000 \mathrm{~m}^{2}\end{array}$ & $\begin{array}{l}\text { Medium } \\
\text { or large } \\
>1000 \mathrm{~m}^{2}\end{array}$ \\
\hline
\end{tabular}

So u r c e: Author.

Ze względu na znaczące różnice wielkości działek w obrębach w typach I, III i IV wyodrębniono podtypy - odpowiednio: Ia i Ib, IIIa i IIIb oraz IVa i IVb.

Końcowym efektem typologii organizacji przestrzeni wypoczynku indywidualnego obrębów geodezyjnych było zaliczenie obrębów do poszczególnych typów oraz sporządzenie kartogramów prezentujących rozkład przestrzenny wydzielonych typów (rys. 1 i rys. 2).

\section{CHARAKTERYSTYKA WYDZIELONYCH TYPÓW}

Typ I - typ obrębu geodezyjnego lub sołectwa, w którym formy osadnictwa wypoczynku indywidualnego (działki letniskowe) rozwinęły się na największą skalę. W obrębach i sołectwach zaliczonych do wymienionego typu zdecydowanie dominuja zwarte kompleksy działek letniskowych, położone głównie na obszarze rozłogów wiejskich i tworzące regularne, zwarte układy przestrzenne, maximum value can be observed in Rąbien $A$ and $B$ where individual tourism settlement covers $28.7 \%$ of its area). The variety found in the garden size criterion has led to the identification of two sub-types; Ia, dominated by medium and large gardens (over $1000 \mathrm{~m}^{2}$ ) and $\mathrm{Ib}$, dominated by small and very small gardens (under $1000 \mathrm{~m}^{2}$ ). Type I is represented by grid squares and sotectwos which were the original cores of summer garden diffusion (figs $1 \& 2$ ) situated next to Łódź, and those close to the most attractive areas - near the river Warta and larger forests.

Type II - The type where individual recreation settlements (summer gardens) have developed on a slightly smaller scale than in type I: $3-10 \%$ of the unit area. Another difference is the distribution of gardens. Type II is dominated by irregular, scattered and mosaic spatial systems, with medium or large gardens (over $1000 \mathrm{~m}^{2}$ ). Type II is represented 


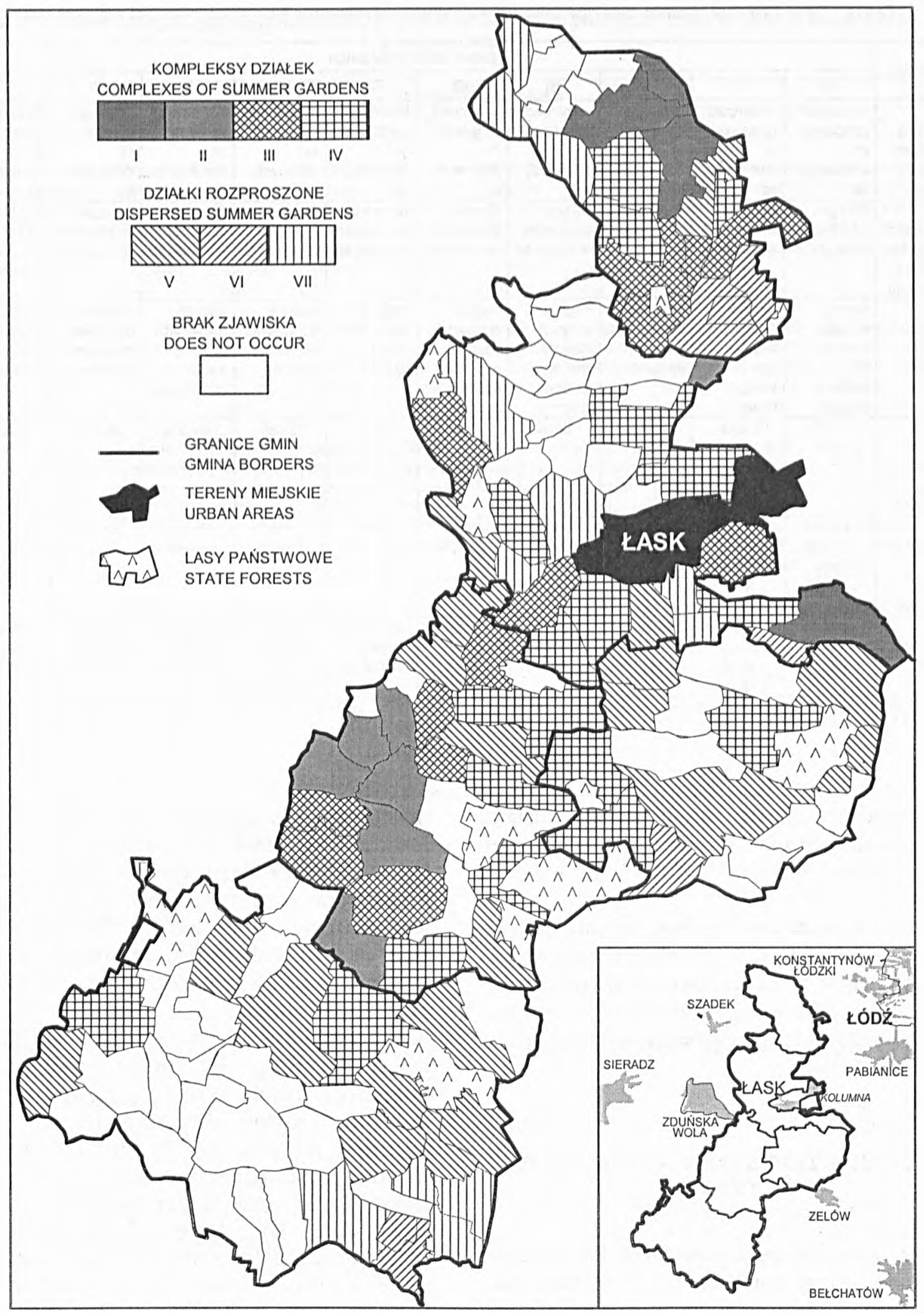

Rys. 1. Rozkład przestrzenny typów organizacji przestrzeni wypoczynku indywidualnego w powiecie łaskim (żr ód ło: opracowanie własne)

Fig. 1. The spatial distribution of the organization of individual recreation space types in Łask powiat (s o u r ce: author) 


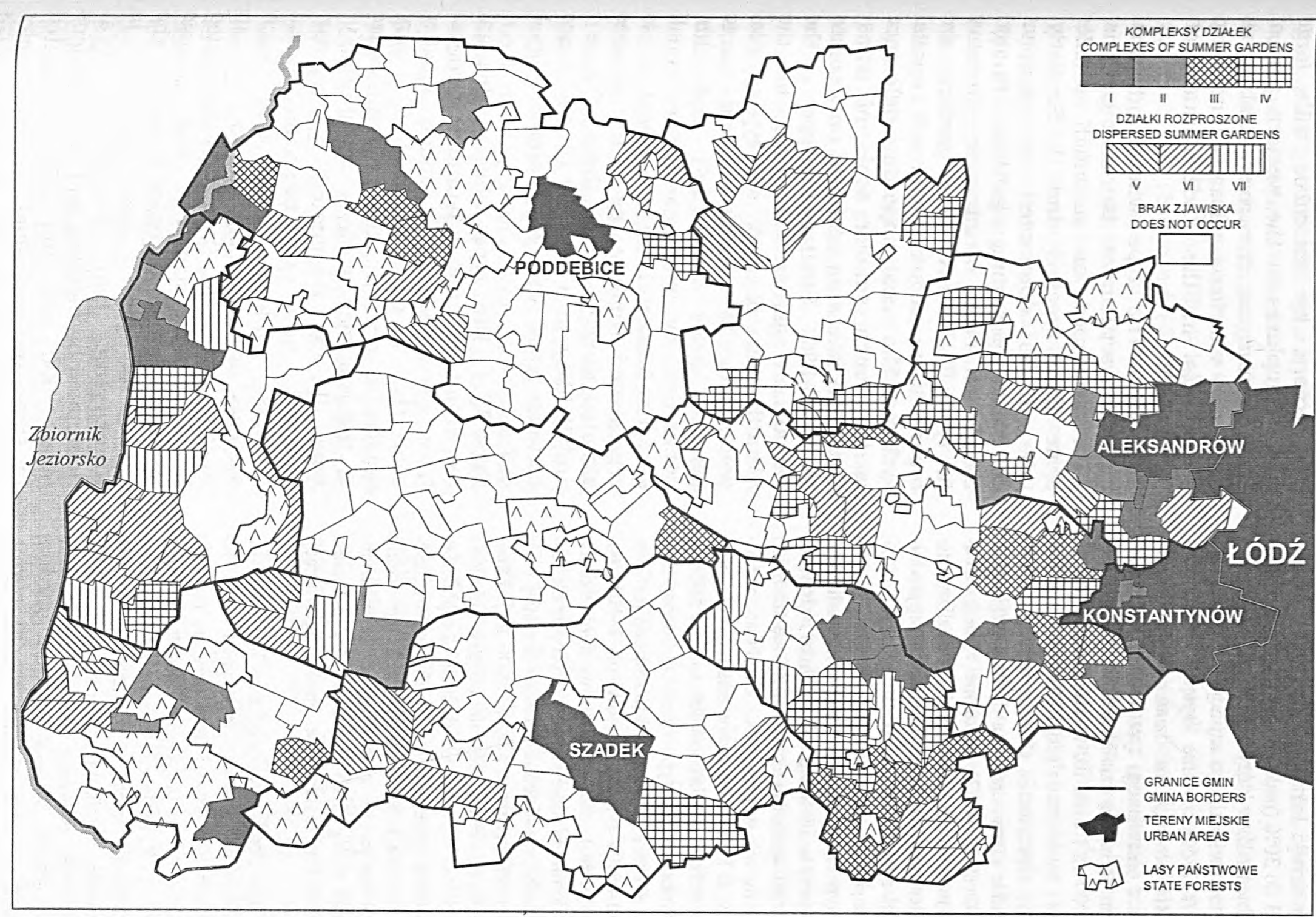

Rys. 2. Rozkład przestrzenny typów organizacji przestrzeni wypoczynku indyiwidualnego w zachodniej części strefy podmiejskiej Łodzi (ż r ó d ło: opracowanie autora) Fig. 2. The spatial distribution of the organization of individual recreation space types in the western sector of Łódź rural-urban zone (s o u r c e: author) 
jedno- lub wieloosiowe. Stopień przekształcenia przez osadnictwo letniskowe pierwotnej przestrzeni obrębów jest duży lub bardzo duży, wielkość zajmowanej przez działki letniskowe przestrzeni obrębu wynosi od 3 do $30 \%$ (maksimum osiąga obręb geodezyjny Rąbień $\mathrm{AB}$, w którym formy turystycznego osadnictwa indywidualnego zajmują aż $28,7 \%$ jego powierzchni). Zróżnicowanie kryterium dominującej wielkości powierzchni działek spowodowało wydzielenie $\mathrm{z}$ omawianego typu dwóch podtypów: Ia, w którym dominują działki średnie i duże (większe niż $1000 \mathrm{~m}^{2}$ ) oraz $\mathrm{Ib}$, w którym przeważają działki małe i bardzo małe (do $1000 \mathrm{~m}^{2}$ ). Charakteryzowany typ reprezentują głównie obręby i solectwa stanowiące pierwotne jądra dyfuzji działek letniskowych (rys. 1, rys. 2), położone w bezpośrednim sąsiedztwie Lodzi, oraz obręby zlokalizowane w pobliżu terenów najatrakcyjniejszych przyrodniczo - w sąsiedztwie rzeki Warty i większych kompleksów leśnych.

Typ II - typ obrębu geodezyjnego lub sołectwa, w którym formy osadnictwa wypoczynku indywidualnego (dzialki letniskowe) rozwinęły się na nieco mniejszą skalę niż w przypadku obrębów zaliczonych do typu I. Przestrzeń indywidualnego osadnictwa wypoczynkowego obrębów lub solectw zaliczonych do wymienionego typu różni się od poprzedniego jedynie skalą (zajmowana przestrzeń jest nieco mniejsza niż w typie I, stanowi od 3-10\% powierzchni obrębu) oraz rozplanowaniem dzialek (w typie II dominują nieregularne, rozproszone i mozaikowe układy przestrzenne działek o średniej i dużej powierzchni, przekraczającej $1000 \mathrm{~m}^{2}$ ). Omawiany typ reprezentują głównie obręby położone w bezpośrednim sąsiedztwie dużych kompleksów leśnych północno-zachodniej i północno-wschodniej części sektora, solectwa z dużymi kompleksami leśnymi położonymi $\mathrm{w}$ zachodniej części powiatu łaskiego nad rzeką Grabią oraz obręby położone w bezpośrednim sąsiedztwie miast aglomeracji łódzkiej (rys. 1, rys. 2).

Typ III - typ obrębu geodezyjnego lub solectwa, w którym formy osadnictwa wypoczynku indywidualnego (działki letniskowe) rozwinęly się na dużo mniejszą skalę niż w przypadku obrębów zaliczonych do typu I i II. Podobnie jak w poprzednich typach, w obrębach i solectwach zaliczonych do typu III zdecydowanie dominuja zwarte kompleksy działek letniskowych, położone głównie na obszarze rozłogów wiejskich. W przeciwieństwie do typu II działki letniskowe tworzą jednak regularne, zwarte układy przestrzenne. Najważniejszym wyróżnikiem jest dużo mniejsza w porównaniu z poprzednimi ty- mainly by grid squares situated next tolarge forest complexes in the northwestern and north-eastern part of the sectors, by solectwos with large forest complexes in the western part of Łask powiat, on the river Grabia, as well as sotectwos situated next to settlements in the Łódż conurbation (figs 1 \& 2).

Type III - The type where individual recreation settlements (summer gardens) have developed on a much smaller scale than types I and II. Similarly, type III is dominated by compact complexes of summer gardens situated mainly on open countryside. Contrary to type II, however, the gardens are organized in regular, compact spatial systems. The most important difference is the much smaller scale of transformation (the area occupied only comes to $0.5 \%-3 \%$ ). Similar to type I, the variety in garden size led to the identification of two sub-types: IIIa, dominated by medium and large gardens (over $1000 \mathrm{~m}^{2}$ ) and IIIb, dominated by small and very small gardens (under $1000 \mathrm{~m}^{2}$ ). Type III is represented mainly by grid squares situated directly beside those of type I and II (they in a way 'fill in' the space between type I and type II areas) - figs 1 \& 2.

Type IV - The type where individual recreation settlements (summer gardens) have developed on a much smaller scale than in types I and II. It is very similar to type III; the only difference is the summer gardens distribution type III was dominated by regular, compact, one- or two-axis spatial systems, while in this type such systems do not occur or only on an insignificant scale. Type IV is dominated by irregular, scattered and mosaic systems. Similar to types I and III, the variety of garden size has led to identifying two sub-types: IVa, dominated by medium and large gardens (over $1000 \mathrm{~m}^{2}$ ) and IVb, dominated by small and very small gardens (under $1000 \mathrm{~m}^{2}$ ). Type IV is represented mainly by grid squares and solectwos 
pami skala przekształceń pierwotnej przestrzeni obrębu (wielkość przestrzeni obrębu zajmowanej przez działki jest niewielka - od 0,5 do 3\%). Podobnie jak w przypadku typu I zróżnicowanie kryterium dominującej wielkości powierzchni działek spowodowato wydzielenie $\mathrm{z}$ omawianego typu dwóch podtypów: IIIa, w którym dominują działki średnie i duże (większe niż $1000 \mathrm{~m}^{2}$ ) oraz IIIb, w którym przeważają działki małe i bardzo małe (do $1000 \mathrm{~m}^{2}$ ). Omawiany typ reprezentują głównie obręby polożone w bezpośrednim sąsiedztwie obrębów zaliczonych do typów I i II (stanowią swoistego rodzaju „wypelnienie” czy „dopelnienie” przestrzeni pozostajacej między wymienionymi typami) - rys. 1, rys. 2 .

Typ IV - typ obrębu geodezyjnego lub sołectwa, w którym formy osadnictwa wypoczynku indywidualnego (działki letniskowe) rozwinęły się na dużo mniejszą skalę niż w przypadku obrębów zaliczonych do typu I i II. Jest to typ bardzo zbliżony do typu III, różni się od niego jedynie rozplanowaniem działek - w typie III dominowały działki tworzace układy regularne, zwarte, jedno- lub wieloosiowe w omawianym typie układów takich nie ma (lub występują marginalnie). Znajdują się w nim natomiast w przewadze dzialki tworzące uklady nieregularne, rozproszone i mozaikowe. Podobnie jak w przypadku typu I i III, zróżnicowanie kryterium dominującej wielkości powierzchni działek spowodowało wydzielenie $\mathrm{z}$ omawianego typu dwóch podtypów: IVa, w którym dominują działki średnie i duże (większe niż $1000 \mathrm{~m}^{2}$ ) oraz IVb z przewagą działek małych i bardzo małych (do $1000 \mathrm{~m}^{2}$ ). Omawiany typ reprezentuja głównie obręby i sołectwa położone w sąsiedztwie miast aglomeracji łódzkiej, jednakże położone w większej odległości od centrum aglomeracji niż obręby czy solectwa zaliczone do poprzednich typów (rys. 1, rys. 2).

Typ V-pierwszy z typów obrębów geodezyjnych lub solectw, w którym formy osadnictwa wypoczynku indywidualnego (dzialki letniskowe) rozwinęly się na bardzo niewielką skalę. W typie tym zdecydowanie dominują działki rozproszone, sporadycznie tworzące niewielkie skupiska (minikompleksy) kilku działek położonych na obszarze rozłogów wiejskich. Stopień przekształcenia pierwotnej przestrzeni obrębu jest bardzo mały, a wielkość zajmowanej przestrzeni obrębu minimalna $(<0,5 \%)$. Wielkość powierzchni działek jest zwykle średnia lub duża, często znacznie przekraczająca $1500 \mathrm{~m}^{2}$. Wymieniony typ jest charakterystyczny dla środkowej części Zachodniego sektora strefy podmiejskiej Łodzi oraz dla środkowej i południowej - peryferyjnej części powiatu laskiego. Spotyka się go również na obsza- near settlements in the Łódż conurbation, but situated further from the conurbation centre than grid squares and solectwos in the previous types (figs $1 \& 2$ ).

Type V - the first where individual recreation settlements (summer gardens) have developed on a very small scale. This type is clearly dominated by scattered summer gardens, occasionally creating small complexes (minicomplexes) situated on open countryside. The original grid square has been transformed very insignificantly, and the gardens occupy less than $0.5 \%$. The garden size is usually medium or large, often exceeding $1500 \mathrm{~m}^{2}$. Type IV is typical of the middle part of the western sector of Łódź urban fringe zone and of the middle and southern (peripheral) part of Łask powiat. It also occurs in the peripheral areas of large, compact complexes of summer gardens (figs $1 \& 2$ ).

Types VI and VII - two types where forms of summer settlement play a marginal or even incidental role. Both the transformation of space and the area occupied are minimal. The individual recreation space solely consists of individual summer gardens, usually large and very large. The only difference between the two types is the location of the gardens in relation to the settlement; in type VI the grid squares are situated on open countryside only, and in type VII - within the settlement. Types VI and VII are characteristic of the middle part of the sector with a poorly developed infrastructure, and also of the squares in the middle and southern part of the Jeziorsko reservoir. As regards Łask powiat, they dominate its southern peripheral part (figs $1 \& 2$ ).

To sum up the spatial distribution of the organization of individual recreation space, there is a quite strong concentration of grid squares and sotectwos, having the most developed forms of recreation space organization, in three parts of the western sector: the distance-related area immediately 
rach peryferyjnych dużych, zwartych kompleksów działek letniskowych (rys. 1, rys. 2).

Typy VI i VII - dwa typy obrębów geodezyjnych lub sołectw, w których formy osadnictwa letniskowego odgrywają rolę marginalną lub wręcz incydentalną. Zarówno stopień przekształcenia przestrzeni przez osadnictwo letniskowe, jak i wielkość zajmowanej przestrzeni obrębu czy sołectwa są minimalne. Przestrzeń wypoczynku indywidualnego w wymienionych typach kreują wyłącznie pojedyncze działki, zwykle duże lub bardzo duże. Wymienione dwa typy różnicuje jedynie położenie działek względem siedliska: obręby zaliczone do typu VI charakteryzuje lokalizacja działek wyłącznie na rozlogach wiejskich, do typu VII - położenie wyłącznie w obrębie siedliska. Wymienione typy są charakterystyczne głównie dla środkowej, słabo zagospodarowanej części sektora oraz dla obrębów położonych w środkowej i poludniowej części obrzeża zbiornika retencyjnego Jeziorsko, w powiecie laskim dominują w sołectwach jego południowej, peryferyjnej części (rys. 1, rys. 2).

Podsumowując przestrzenne rozmieszczenie wydzielonych typów organizacji przestrzeni wypoczynku indywidualnego należy stwierdzić, że charakteryzuje się ono dość silną koncentracją obrębów geodezyjnych i solectw, o najbardziej rozwiniętych formach organizacji przestrzeni wypoczynku indywidualnego - w trzech rejonach zachodniego sektora: związanym z czynnikiem odległościowym obszarze położonym w bezpośrednim sąsiedztwie Łodzi (strefa do $30 \mathrm{~km}$ od centrum Łodzi) oraz związany$\mathrm{mi}$ z walorami przyrodniczymi terenami położonymi w północno-zachodniej i poludniowo-zachodniej części sektora oraz $\mathrm{w}$ związanej $\mathrm{z}$ walorami przyrodniczymi (rzeka Grabia i duże kompleksy leśne) zachodniej części powiatu łaskiego. next to Łódż (up to $30 \mathrm{~km}$ from Łódź centre), the areas situated in the northwestern and south-western parts of the sector due to their natural assets, and the western part of Łask powiat also due to its natural assets (the river Grabia and large forest complexes).

\section{BIBLIOGRAFIA - BIBLIOGRAPHY}

DzIEGIEĆ E., 1988, Przemiany wsi Chałupy 1 Kuźnica pod wpływem rozwoju turystyki, Turyzm, 4.

DzIEGIEĆ E., 1989. Przemiany wsi polożonych w strefie krajobrazowej pojezierzy, Rocznik Centralnego Programu Badań Podstawourych, Instytut Turystyki, Warszawa.

KOWALCZYK A., 1994, Geograficzno-spoteczne problemy zjawiska "drugich domów", Wydawnictwo Uniwersytetu Warszawskiego, Warszawa.

Liszewski S., 1995, Przestrzeń turystyczna, Turyzm, 5/2.

MATCZAK A., 1981, Tereny wypoczynkowe w strefie podmiejskiej Lodzi, Miasto, 31, 6,

MATCZAK A., 1982, Funkcja wypoczynkowa strefy podmiejskiej Łodzi, praca doktorska wykonana w Instytucie Geografii Ekonomicznej 1 Organizacji Przestrzeni UL, maszynopis.
MATCZAK A., 1984, Próba wykorzystania analizy morfologicznej do określenia funkcji wypoczynkowej osiedli w strefie podmiejskiej Lodzi, Problemy Turystyki, 2.

MATCZAK A., 1985, Funkcja wypoczynkowa strefy podmiejskiej Łodzi, Acta Universitatis Lodziensis. Folia Geographica, 5.

MATCZAK A., 1986, Budownictwo letniskowe w strefie podmiejskiej Lodzi, Acta Universitatis Lodziensis. Folia Geographica, 7.

MATCZAK A., 1995, Kolonizacja turystyczna obszarów wiejskich w strefie podmiejskiej Lódzi, [w:] Kowalczyk A. (red.), Zmiany $w$ przestrzeni geograficznej $w$ warunkach transformacji społeczno-ekonomicznej (na przy. kładzie obszarów wiejskich), Wydawnictwo Uniwersy" tetu Warszawskiego, Warszawa. 
MATCzaK A., 1987, Próba określenia funkcji wypoczynkowej osiedli podmiejskich na przykładzie Kolumny, Acta Universitatis Lodziensis. Turyzm, 3.

STACHOWSKI J., 1992, Ewolucja struktury przestrzennofunkcjonalnej osiedla pod wplywem rozwoju rekreacji na przykladzie wsi Charzykowy koło Chojnic, Turyzm, $2 / 2$.

SzKUP R., 2003, Ksztattowanie podmiejskiej przestrzeni wypoczynkowej. Przyktad zachodniego sektora strefy podmiejskiej Łodzi, Wydawnictwo Uniwersytetu Lódzkiego.

WiLuS R., 1997, Rozwój funkcji turystycznej $w$ dolinie rzeki Warty na odcinku od Dziatoszyna do Uniejowa, ser. „Szlakami Nauki”, 24, Lódzkie Towarzystwo Naukowe, Łódź.
WhODARCZYK B., 1995, Stan zagospodarowania turystycznego w województwach Polski środkowej, [w:] Studium wiedzy o regionie łódzkim. Rozwój turystyki $w$ regionie tódzkim, Łódzkie Towarzystwo Naukowe, Łódź.

WlodarczYK B., 1998, Przemiany form aktywności turystycznej na obszarze pótnocnej części krawędzi Wyżyny Łódzkiej, maszynopis pracy doktorskiej wykonanej w Katedrze Geografil Miast 1 Turyzmu Uniwersytetu Lódzkiego.

WOJCIECHOWSKA J., 1998, Kolonizacja turystyczna terenów nadpilicznych, ser. „Szlakami Nauki”, 26, Lódzkie Towarzystwo Naukowe, Łódż. 